\title{
Adalimumab Biosimilar-Induced Severe Paradoxical Palmoplantar Pustulosis in a Patient with Psoriasis and Psoriatic Arthritis Successfully Treated with Ixekizumab
}

\author{
Spyridon Gkalpakiotis (D) · Marketa Fridman · Simona Tivadar
}

Received: October 28, 2021 / Accepted: December 22, 2021 / Published online: January 24, 2022

(c) The Author(s) 2021

\begin{abstract}
Psoriasis vulgaris is a chronic immune-mediated inflammatory disease of the skin. Biologic therapy has been available for more than 10 years and has become one of the standard treatments for patients with moderate to severe psoriasis. Initially, only biologics against tumour necrosis factor alpha (TNF- $\alpha$ ) were used, and only later did drugs against different interleukins (ILs), including IL-17 or IL-23, became available. The side effects of biologic therapy include paradoxical adverse events (PAEs), such as palmoplantar pustular reaction, especially with anti-TNF- $\alpha$ drugs. We present the case of a 49-year-old female patient with diabetes and psoriasis and psoriatic arthritis treated with an adalimumab biosimilar who developed a severe PAE of the palmoplantar pustular type. Treatment with adalimumab was stopped and the patient switched to ixekizumab which was successful. When a paradoxical reaction develops during biologic therapy, especially when it is severe as in our patient, switching to another class of biologics is advised.
\end{abstract}

S. Gkalpakiotis $(\bowtie) \cdot$ M. Fridman · S. Tivadar Department of Dermatovenereology, Third Faculty of Medicine, Charles University-Kralovske Vinohrady University Hospital, Prague, Czech Republic

e-mail: spyros@centrum.cz
Keywords: Paradoxical reaction; Adalimumab; Palmoplantar pustulosis; Ixekizumab

\section{Key Summary Points}

Biologic therapy is highly effective for the treatment of psoriasis but has been linked with paradoxical adverse events (PAEs).

PAEs of the palmoplantar pustular type have been described mainly with antitumour necrosis factor alpha biologic agents, but similar cases have been reported with anti-interleukin-17 therapy.

In severe cases of PAEs a switch to a biologic with a different mechanism of action is suggested.

\section{INTRODUCTION}

Psoriasis vulgaris is a chronic immune mediated inflammatory disease of the skin affecting approximately $2-3 \%$ of the general population [1]. Biologic therapy is routinely used for the treatment of moderate to severe psoriasis [2]. Different biologic drugs are available with specific mechanisms of action, such as blocking the activity of tumour necrosis factor alpha (TNF- $\alpha$ ), interleukin (IL)-17, IL-23 or IL-12/23 
[2]. Anti-TNF- $\alpha$ drugs, such as adalimumab, have been available for over 10 years and are being used to treat different immune-mediated inflammatory diseases, including psoriasis, psoriatic arthritis, hidradenitis suppurativa and inflammatory bowel disease (IBD) [3]. One of the side effects of biologic drugs, and especially of anti-TNF- $\alpha$ therapy, are several "paradoxical" adverse events (PAEs), such as exacerbation of the disease for which the drug is used, change in disease phenotype or onset of another condition $[3,4]$.

\section{CASE REPORT}

We report the case of a 49-year-old female patient with diabetes and psoriasis and psoriatic arthritis (PsA) who had a history of intolerance to phototherapy and methotrexate. The patient had moderate to severe psoriasis with a Psoriasis Area and Severity Index (PASI) score of 14.8, thus we decided to initiate treatment with an adalimumab biosimilar. The patient showed a good response after 8 weeks of therapy, but on the tenth week she developed a pustular eruption on both the palms of her hands and soles of her feet. In response, we added topical calcipotriol/betamethasone foam to the therapeutic regimen, but the condition rapidly worsened with massive pustulation, exacerbation of plaque psoriasis, swelling and pain of the joints (Fig. 1a-d), which led to the decision to discontinue adalimumab. Blood results revealed neutrophilia $\left(7.04 \times 10^{9} / \mathrm{L}\right)$ and increased C-reactive protein $(69.1 \mathrm{mg} / \mathrm{L})$, but as no signs of infection were present, we assigned these results to the skin lesions and to the exacerbation of PsA. After 2 weeks, the pain and swelling of the joints got worse and the skin condition showed no improvement; the decision was taken to switch the patient to ixekizumab on the label dose for psoriasis. A rapid improvement of the skin lesions was observed after 7 days. The disease became stable with minor pustules on the soles. After 16 weeks on ixekizumab, plaque psoriasis and lesions on the palms of her hands were completely healed (Fig. 2c, d) although some hyperkeratosis with minimum pustules was still present on the soles of her feet (Fig. 2a,

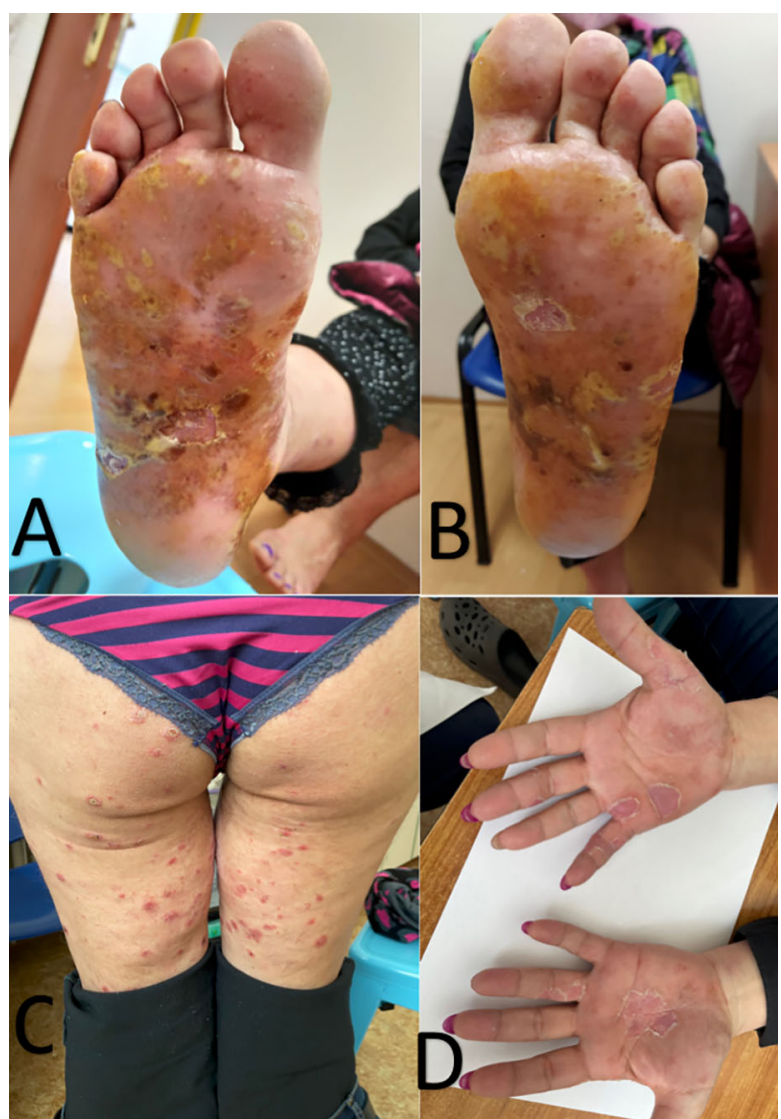

Fig. 1 a, b Diffuse pustulation with erythema and exfoliation of the soles of both feet. c Exacerbation of plaque psoriasis on the lower extremities. $\mathbf{d}$ Pustules and hyperkeratotic lesions on the palms of the hands

b). Swelling and pain of the joints also significantly improved.

The patient described herein provided informed consent to publish the details of her case.

\section{DISCUSSION}

Paradoxical adverse events can be defined as a new onset or worsening of a pathological condition during therapy with a biologic agent that under normal conditions responds well to this class of drug [4]. Different reactions have been described during anti-TNF-a treatment, with the most common being psoriasiform and pustular eruptions $[5,6]$. Change in the phenotype of the disease for which the biologic is used, such 


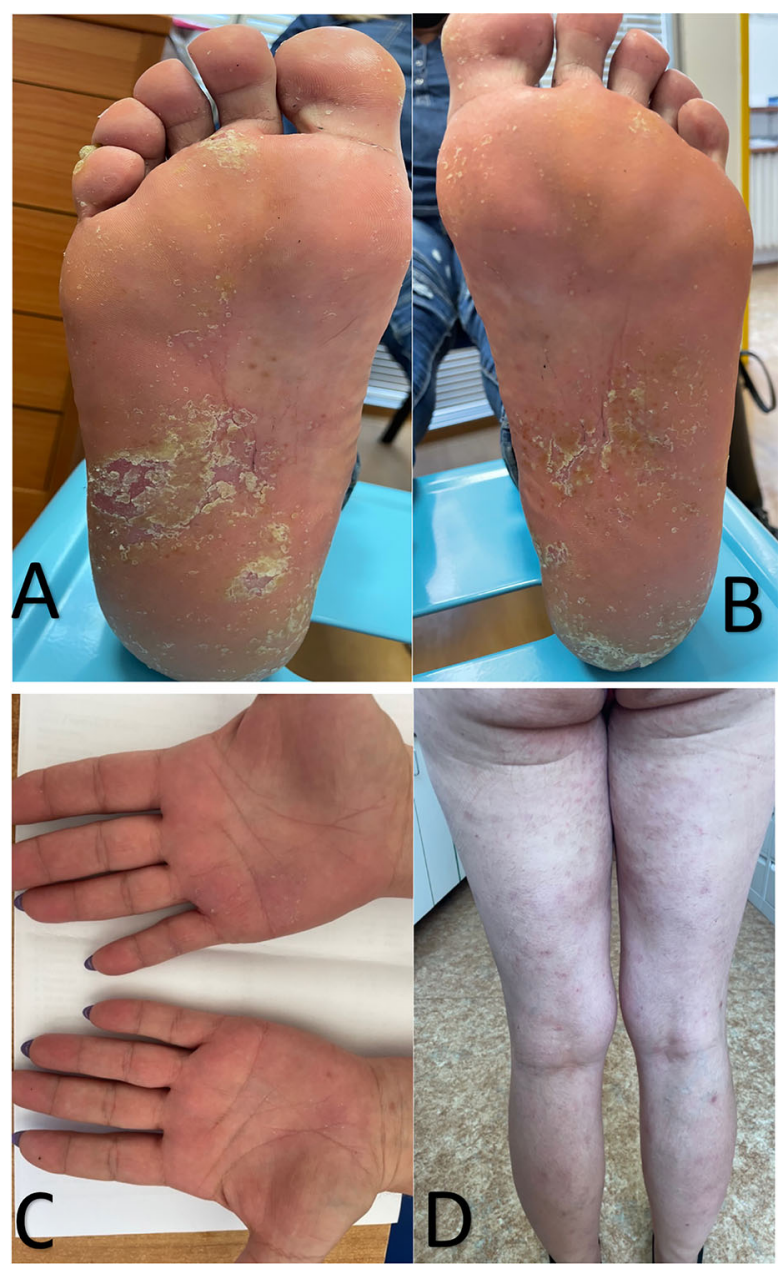

Fig. 2 a, b Significant improvement of lesions on the soles of the feet. c Complete clearance of plaque psoriasis on the lower extremities. $\mathbf{d}$ Complete resolution of the lesions on the palms of the hands

as new onset of palmoplantar pustulosis, in a patient treated for psoriasis is quite rare, with these reactions more often seen in patients treated with anti-TNF- $\alpha$ for rheumatic diseases or for IBD [7, 8]. Our patient had psoriasis as well as PsA.

A number of authors have attempted to explain the immunopathogenesis of paradoxical psoriasiform skin lesions. One proposed theory is that plasmacytoid dendritic cells increase the production of interferon gamma secondary to TNF- $\alpha$ antagonism, subsequently leading to $\mathrm{T}$-cell activation and a further increase in TNF- $\alpha$ production [9]. A second hypothesis is that the increased production of
T-helper 17 cells (Th17) and downregulation of regulatory T cells (Tregs) after blockade of TNF- $\alpha$ can lead to increased production of IL-17 [10]. This hypothesis is supported by the rapid improvement observed in our patient after the initiation of treatment with ixekizumab, which is a humanized monoclonal antibody against IL-17A. Tillack et al. described increased levels of IL-36 $\gamma$ and IL-17C in anti-TNF- $\alpha$-induced psoriasiform lesions in patients with Crohn's disease [11]. Paradoxical reactions of the palmoplantar pustular type have also been newly described with all anti-IL-17 drugs (ixekizumab, secukinumab and brodalumab) [12, 13], with the authors explaining that the mechanism of PAEs in anti-IL-17 drugs may be due to a paradoxical increase of TNF- $\alpha$ through blockade of IL-17A. In most of the published cases of paradoxical reactions with anti-IL-17 drugs the patients were switched to either anti-IL-12/23 or anti-IL-23 drug, with the exception of one patient who developed hidradenitis suppurativa during secukinumab therapy and was successfully treated with adalimumab [12-14]. Our patient showed a fast response to treatment following the switch to ixekizumab from adalimumab, which shows that therapy with an antiIL-17A drug could be a treatment option for a paradoxical reaction of the palmoplantar pustulosis type during anti-TNF- $\alpha$ therapy for patients with psoriasis even though PAEs have also been described with anti-IL-17 drugs. Our case report adds evidence to the existing literature and suggests that when a class-specific adverse event occurs, the biologic agent being used should be switched to another biologic with a different mechanim of action [15].

\section{CONCLUSIONS}

Paradoxical adverse events, especially those of the palmoplantar pustulosis type, have been described with different biologic drugs, but mostly with anti-TNF- $\alpha$. Topical therapy can be sufficient to control the PAE in some cases, but if a severe exacerbation develops, as in our patient, switching to a biologic drug of a different class is suggested. Further investigation is needed to better understand the 
pathophysiology of paradoxical reactions and ideally identify markers which can suggest which patients are at higher risk of developing PAEs when treated with a specific class of biologic.

\section{ACKNOWLEDGEMENTS}

We thank the patient described in this case report.

Funding. No funding or sponsorship was received for this study or publication of this article.

Authorship. All named authors meet the International Committee of Medical Journal Editors (ICMJE) criteria for authorship for this article, take responsibility for the integrity of the work as a whole, and have given their approval for this version to be published.

Author Contributions. Spyridon Gkalpakiotis designed and wrote the paper. Simona Tivadar and Marketa Fridman contributed to the design of the paper.

Disclosures. Spyridon Gkalpakiotis has served as consultant, speaker and/or investigator for Abbvie, Celgene, Eli Lilly, Janssen, Leo Pharma, Novartis, Pfizer and UCB. Simona Tivadar and Marketa Fridman have nothing to disclose.

Compliance with Ethics Guidelines. The patient described herein provided informed consent to publish the details of her case.

Data Availability. The datasets generated during and/or analyzed during the current study are available from the corresponding author on reasonable request.

Open Access. This article is licensed under a Creative Commons Attribution-NonCommercial 4.0 International License, which permits any non-commercial use, sharing, adaptation, distribution and reproduction in any medium or format, as long as you give appropriate credit to the original author(s) and the source, provide a link to the Creative Commons licence, and indicate if changes were made. The images or other third party material in this article are included in the article's Creative Commons licence, unless indicated otherwise in a credit line to the material. If material is not included in the article's Creative Commons licence and your intended use is not permitted by statutory regulation or exceeds the permitted use, you will need to obtain permission directly from the copyright holder. To view a copy of this licence, visit http://creativecommons.org/licenses/by$\mathrm{nc} / 4.0 /$.

\section{REFERENCES}

1. Parisi R, Iskandar IYK, Kontopantelis E, et al. National, regional, and worldwide epidemiology of psoriasis: systematic analysis and modelling study. BMJ. 2020;369:m1590.

2. Armstrong AW, Soliman AM, Betts KA, et al. Comparative efficacy and relative ranking of biologics and oral therapies for moderate-to-severe plaque psoriasis: a network meta-analysis. Dermatol Ther (Heidelb). 2021;11(3):885-905.

3. Wendling D, Prati C. Paradoxical effects of antiTNF- $\alpha$ agents in inflammatory diseases. Expert Rev Clin Immunol. 2014;10(1):159-69.

4. Puig L, Gulliver W. Adverse reactions to biologics. In: Puig L, Gulliver W, editors. Adverse reactions to biologics. Current problems in dermatology, vol 53. Basel: Karger; 2018. p. 49-63

5. Zangrilli A, Bavetta M, Mazzilli S, Garofalo V, Bianchi L. Paradoxical case effects of psoriasis following adalimumab therapy: a case series. Dermatol Ther. 2018;31(6):e12729.

6. Seol JE, Park IH, Lee W, Kim H, Jung SY, Wang HY. Palmoplantar pustulosis induced by both adalimumab and golimumab for treatment of ankylosing spondylitis. Ann Dermatol. 2016;28(4):522-3.

7. Ko JM, Gottlieb AB, Kerbleski JF. Induction and exacerbation of psoriasis with TNF-blockade therapy: a review and analysis of 127 cases. J Dermatolog Treat. 2009;20:100-8.

8. Wollina U, Wollina U, Hansel G, et al. Tumor necrosis factor-alpha inhibitor-induced psoriasis or psoriasiform exanthemata: first 120 cases from the 
literature including a series of six new patients. Am J Clin Dermatol. 2008;9:1-14.

9. Collamer AN, Battafarano DF. Psoriatic skin lesions induced by tumor necrosis factor antagonist therapy: clinical features and possible immunopathogenesis. Semin Arthritis Rheum. 2010;40:233-40.

10. Ma HL, Napierata L, Stedman N, et al. Tumor necrosis factor alpha blockade exacerbates murine psoriasis-like disease by enhancing Th17 function and decreasing expansion of Treg cells. Arthritis Rheum. 2010;62(2):430-40.

11. Tillack C, Ehmann LM, Friedrich M, et al. Anti-TNF antibody-induced psoriasiform skin lesions in patients with inflammatory bowel disease are characterised by interferon- $\gamma$-expressing Th1 cells and IL-17A/IL-22-expressing Th17 cells and respond to anti-IL-12/IL-23 antibody treatment. Gut. 2014;63:567-77.
12. Mössner R, Pinter A. Paradoxical palmoplantar pustulosis induced by secukinumab and brodalumab: a report of three cases. Eur J Dermatol. 2020. https://doi.org/10.1684/ejd.2020.3702.

13 Hlaca N, Zagar T, Kastelan M, Brajac I, Prpic-Massari L. Ixekizumab-induced paradoxical pustular reaction successfully treated with guselkumab. Clin Exp Dermatol. 2021;46(8):1572-3. https://doi.org/10. 1111/ced.14757.

14 Babino G, D'Ambra I, Fulgione E, Alfano R, Verolino $P$, Argenziano G. Secukinumab-induced paradoxical hidradenitis suppurativa successfully treated with adalimumab. Int J Dermatol. 2021. https://doi.org/ 10.1111/ijd.15730 (Epub ahead of print).

15. Tsai YC, Tsai TF. Switching biologics in psoriasispractical guidance and evidence to support. Expert Rev Clin Pharmacol. 2020;13(5):493-503. 